
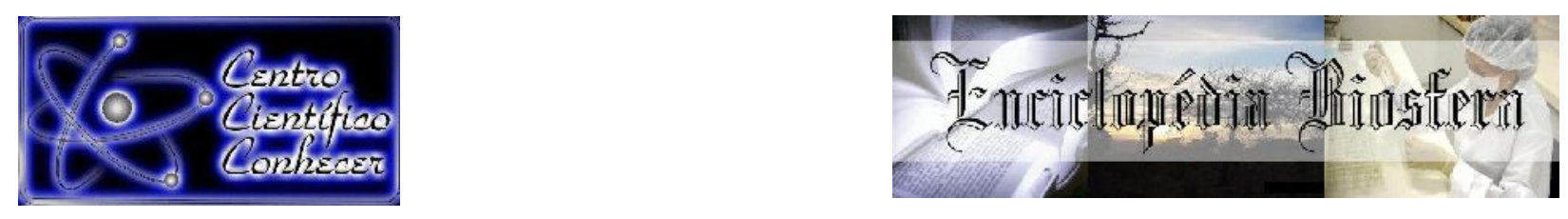

\title{
ÁCIDO INDOLBUTÍRICO NO ENRAIZAMENTO DE ESTACAS DE UMBUZEIRO NO ESTÁDIO DE REPOUSO VEGETATIVO
}

\author{
Elma Machado Ataíde ${ }^{1}$, Jackson Mirellys Azevêdo Souza ${ }^{2}$, Débora Costa Bastos ${ }^{3}$ \\ Alexandre Maniçoba da Rosa Ferraz Jardim ${ }^{4}$, Rosemeire Santos Costa ${ }^{5}$ \\ ${ }^{1}$ Professora Doutora do curso de Agronomia da Universidade Federal Rural de \\ Pernambuco (UFRPE), Serra Talhada-PE, Brasil. E-mail: elma.ataide@ufrpe.br \\ ${ }^{2}$ Pós-Doutorado/Universidade Estadual Paulista, Botucatu-SP, Brasil. \\ ${ }^{3}$ Pesquisadora Pós-Doutorado da Embrapa Semiárido, Petrolina-PE, Brasil. \\ ${ }^{4}$ Doutorando em Ciências Agrárias/UFRPE, Recife-PE, Brasil. \\ ${ }^{5}$ Mestranda em Produção Vegetal/UFRPE, Serra Talhada-PE, Brasil.
}

\section{Recebido em: 15/11/2020 - Aprovado em: 15/12/2020 - Publicado em: 30/12/2020 \\ DOI: 10.18677/EnciBio_2020D2}

\begin{abstract}
RESUMO
O umbuzeiro é uma espécie endêmica da Caatinga, com potencial a ser explorado economicamente pelos agricultores da região Nordeste. No entanto, o extrativismo dos frutos tem levado ao declínio da cultura. Assim, é importante utilizar tecnologias visando a sua preservação, como por exemplo, a produção de mudas por meio da propagação vegetativa, o que permitirá a produção de clones, produção precoce e maior produtividade. Desta forma, o trabalho teve como objetivo avaliar o efeito do ácido indolbutírico (AIB) sobre o desenvolvimento de estacas de umbuzeiro no estádio de repouso vegetativo. A pesquisa foi realizada em viveiro telado com $70 \%$ de sombreamento. Utilizou-se o método de estaquia, sendo as estacas coletadas em agosto, quando se encontravam no estádio fisiológico de repouso vegetativo. Trinta estacas foram submetidas à aplicação de $9.000 \mathrm{mg} \mathrm{L}^{-1}$ de AIB, por imersão por $10 \mathrm{seg}$. em solução hidroalcóolica. Para efeito de comparação (testemunha), um número igual de estacas foi submetido à imersão em solução hidroalcóolica sem o regulador. Aos 120 dias, avaliou-se o percentual de estacas enraizadas e com brotações; comprimento de raízes e de brotações; número de raízes e de brotações; e massa fresca e seca de raízes e de brotações. Com base nos resultados, observou-se que a utilização de AIB na concentração de $9.000 \mathrm{mg} \mathrm{L}^{-}$ 1 não promoveu maior enraizamento ou brotação de estacas. Portanto, nas condições deste estudo, não se recomenda o uso de AIB para a promoção do enraizamento de estacas de umbuzeiro coletadas no estádio de repouso vegetativo.

PALAVRAS-CHAVE: Estaquia, regulador vegetal, Spondias tuberosa Arruda.
\end{abstract}

\section{INDOLBUTYRIC ACID IN THE ROOTING OF UMBUZEIRO CUTTINGS IN THE VEGETATIVE REPOSE STAGE}

\begin{abstract}
The umbu plant (Spondia tuberosa) is an endemic species of the Caatinga biome, with potential for economic use by farmers in northeastern Brazil. However, fruit exploitation has led to the decline of native plants. It is important to use technologies to preserve these plants, such as the production of seedlings through vegetative
\end{abstract}


propagation. This will allow to produce clones, early production and increased productivity. Thus, the study aimed to evaluate the effect of indolbutyric acid (IBA) on the development of umbu plant cuttings in the vegetative repose stage. The research was carried out in a shade net house ( $70 \%$ shading). The cutting method was used, and the cuttings were collected in August, when they were in the physiological stage of vegetative repose. Thirty cuttings were subjected to the application of $9,000 \mathrm{mg} \mathrm{L}$ 1 of IBA by immersion for $10 \mathrm{sec}$ in hydroalcoholic solution. For comparison (control), an equal number of cuttings were subjected to immersion in a hydroalcoholic solution without IBA. At 120 days, the percentage of cuttings rooted and with shoots, length of roots and shoots, number of roots and shoots, and fresh and dry mass of roots and shoots were evaluated. Based on the results, it is observed that the use of IBA $(9,000$ $\mathrm{mg} \mathrm{L-1)}$ does not promote better rooting and sprouting of cuttings of umbuzeiro. Therefore, under the conditions of this study, the use of IBA is not recommended to promote the rooting of umbuzeiro cuttings collected in the vegetative repose stage.

KEYWORDS: development, plant regulator, Spondias tuberosa Arruda.

\section{INTRODUÇÃO}

Dentre as frutíferas nativas com potencial de serem exploradas economicamente, pode-se destacar o umbuzeiro (Spondias tuberosa Arruda Câmara - Anacardiaceae), espécie tropical xerófita, endêmica da Caatinga (LIMA et al., 2015; MERTENS et al., 2016). Esta espécie possui várias opções de uso pelos agricultores da região semiárido brasileira. Os frutos são bastante aceitos para o consumo na forma de fruta fresca, como processados para produção de geléias, doces, sucos, sorvetes e umbuzada (MERTENS et al., 2016). Constitui, portanto, em uma importante opção a expansão desta cultura no semiárido nordestino.

Nesta região, o desenvolvimento sustentável das comunidades rurais tem sido prioridade, principalmente com frutas nativas, o que favorece a inclusão socioprodutiva, especialmente na geração de renda familiar. Nesta perspectiva, o umbuzeiro é uma excelente opção para o fortalecimento da agricultura familiar no semiárido (COOPERCUC, 2020). Portanto, é uma importante perspectiva a expansão desta cultura nas diversas localidades do Nordeste, já que os frutos possuem apelo 'exótico', para mercados de outras regiões do Brasil, como São Paulo e Rio de Janeiro, bem como, exporta doces, geléias e compotas de umbu para os principais mercados externos da União Européia, como Alemanha, França, Áustria e Reino Unido (ARAÚJO, 2016). As principais regiões produtoras de umbu são no Sudoeste e Norte do estado da Bahia, com comercialização do fruto, principalmente, em feiras livres na forma de fruta fresca, como destinado ao processamento de polpa (ATAÍDE et al., 2017). Atualmente é também utilizado na fabricação de cerveja artesanal.

Apesar desta frutífera ser uma alternativa para geração de renda das comunidades rurais do semiárido, observa-se grande devastação, devido ao extrativismo desordenado de frutos, o que tem levado ao declínio da cultura nos últimos anos. Todavia, alternativamente o umbuzeiro tem potencial para ser cultivado em larga escala tanto em sistemas agroflorestais, como em reflorestamentos (ANDRADE et al., 2013). A espécie apresenta boa adaptabilidade a longos períodos de estiagem, cujo mecanismo de defesa se dar por meio de raízes modificadas em xilopódios (ANTUNES et al., 2016). Em termos de cultivos comerciais, recentemente as áreas de plantio têm sido incrementadas com novos produtores orgânicos no estado da Bahia, visando agregar valor ao produto e incrementar a renda familiar. 
Diante do uso indiscriminado das espécies nativas, é imprescindível difundir novas tecnologias buscando sua preservação, como a produção de mudas de qualidade, as quais poderão ser utilizadas para formação de novos plantios, bem como em projetos de reflorestamento. Especificamente na cultura do umbuzeiro, a produção de mudas é dificultada pela dormência das sementes, a qual resulta em lenta emergência e plantas desuniformes, além da variabilidade genética e longo período de juvenilidade. Neste cenário, técnicas de propagação vegetativa podem ser utilizadas visando a produção de mudas genotipicamente idênticas às plantas matrizes, conservando-se as características desejáveis e a antecipação da produção de frutos, por reduzir o período juvenil (FONSECA et al., 2019).

A exploração das frutas nativas vem sendo bastante atrativa, no entanto, a produção natural não atende à demanda da agroindústria (MENDES; SOUZA, 2020). Portanto, os produtores têm buscado tecnologias alternativas para a produção de mudas de qualidade e precocidade de produção, principalmente para a cultura do umbuzeiro. Dos métodos de propagação vegetativa utilizados para a produção de mudas de umbuzeiro, destaca-se a estaquia. Contudo, o sucesso desta técnica depende de fatores endógenos e externos (RIOS et al., 2012). Segundo Denaxa et al. (2012), os fatores endógenos são inerentes à própria planta, como o balanço hormonal e nutricional da planta matriz, por sua vez, os fatores externos são inerentes às condições ambientais, como a temperatura e a umidade do ar.

As condições nutricionais e o balanço hormonal do material propagativo são diretamente influenciados pelos estádios fenológicos das estacas, bem como, a época da coleta. Em espécies do gênero Spondia, as coletas dos propágulos devem ser realizadas antes da emissão das brotações dos ramos, das folhas e das flores, já que na fase reprodutiva, as reservas da planta, como os aminoácidos, as proteínas e os carboidratos são direcionados para a formação destes órgãos (SOUZA; ARAÚJO, 1999). Ressalta-se a importância do balanço hormonal para promover o equilíbrio dos promotores e inibidores do processo de iniciação radicular das estacas.

Uma prática que pode ajudar no processo de formação das mudas, segundo Tecchio et al. (2015), é o emprego de reguladores vegetais. Dos fitorreguladores utilizados na propagação de frutíferas por estaquia, a auxina é o mais utilizado para estimular a formar as raízes secundárias e nódulos radiculares. Contudo, os resultados podem variar em função da espécie, fatores abióticos, época de floração e frutificação, estádio fenológico da estaca, métodos de aplicação do regulador e o substrato (OINAM et al., 2011). Dentre os reguladores vegetais existentes, o ácido indolbutírico (AIB) é uma das principais auxinas sintéticas utilizada na produção de mudas nas diversas espécies.

Em pesquisa com a cultura do umbuzeiro, Rios et al. (2012) avaliaram o tamanho das estacas (10 e $20 \mathrm{~cm}$ ), as concentrações de AIB 0, 1.500, 3.000, 4.500 e $6.000 \mathrm{mg} \mathrm{L}^{-1}$ e períodos de coleta das estacas (março e setembro). Estes autores observaram maior formação de raízes em propágulos coletados em março, com tamanho de $20 \mathrm{~cm}$ e submetidas ao tratamento com $6.000 \mathrm{mg} \mathrm{L}^{-1}$ de AIB, contudo o maior percentual de enraizamento obtido foi de somente 30\%. Já Ataíde et al. (2017) não obtiveram brotações e enraizamento satisfatórios em experimento com estacas de umbuzeiro propagadas em três épocas de coletas (períodos reprodutivo, vegetativo e de repouso), submetidas à concentrações de AIB $(0,3.000,6.000$ e $9.000 \mathrm{mgL}^{-1}$ ) e cultivadas em três tipos de substratos (areia lavada, esterco de caprino e fibra de coco).

Por outro lado, Véras et al. (2018) conseguiram maior percentagem de enraizamento $(47,20 \%)$ de estacas de umbuzeiro quando submetida a combinação 
de ethephon e AIB, nas concentrações de $100 \mathrm{mgL}^{-1}$ e $6.000 \mathrm{mg} \mathrm{L}^{-1}$, respectivamente. Rocha et al. (2019) conduzindo trabalho com estacas de umbuzeiro e cajá-manga ( $S$. dulcis), testaram seis doses de ácido indol-3-acético (AIA) $\left(0,2,4,6\right.$ e $\left.10 \mathrm{~g} \mathrm{~L}^{-1}\right)$ e três tempos de imersão (8, 16 e 24 segundos), sendo os melhores resultados de enraizamento e brotação obtidos com a dose de $10 \mathrm{~g} \mathrm{~L}^{-1}$ de AIA e tempo de imersão de 16 segundos.

Diante do exposto, pesquisas visando o aperfeiçoamento das técnicas de propagação são importantes já que os resultados encontrados por muitos autores são ainda divergentes. Face ao exposto, objetivou-se neste estudo avaliar o ácido indolbutírico no enraizamento de estacas de umbuzeiro no estádio de repouso vegetativo.

\section{MATERIAL E MÉTODOS}

A pesquisa foi realizada em condições de viveiro telado, com $70 \%$ de sombreamento, na Unidade Acadêmica de Serra Talhada, pertencente à Universidade Federal Rural de Pernambuco (UAST/UFRPE), município de Serra Talhada, PE, situado no Sertão Pernambucano, Alto do Pajeú. A região localiza-se nas coordenadas geográficas a $07^{\circ} 59^{\prime} 31^{\prime \prime}$ de latitude Sul e $38^{\circ} 17^{\prime} 54^{\prime \prime}$ de longitude Oeste, com altitude média de $530 \mathrm{~m}$. O clima da região é classificado como semiárido com chuvas concentradas nos meses de março e abril, precipitação média anual de $550 \mathrm{~mm}$, temperatura média de $32{ }^{\circ} \mathrm{C}$, umidade relativa do ar de $62,8 \%$ e a vegetação caatinga hiperxerófita.

Foi utilizado o método de propagação por estaquia, utilizando-se estacas coletadas no período de repouso vegetativo (agosto) a partir de plantas adultas situadas na UAST. A coleta dos propágulos do umbuzeiro foi realizada nas primeiras horas da manhã. Em seguida foram transportadas para o laboratório da UAST.

As estacas foram padronizadas com comprimento de $20 \mathrm{~cm}$ (RIOS et al., 2012). Este procedimento foi realizado com tesoura de poda, sendo realizado um corte reto no ápice e na base em bisel. Posteriormente, as estacas (30) foram submetidas ao tratamento com solução hidroalcóolica (50\% v/v) contendo $9.000 \mathrm{mg}$ $\mathrm{L}^{-1}$ de AIB. Para efeito de comparação (testemunha), um número igual de estacas foi submetido à imersão na solução hidroalcoólica sem AIB. Em ambos os casos, a base das estacas $(2 \mathrm{~cm})$ permaneceu imersa na solução por 10 segundos.

0 estaqueamento foi realizado em bandejas plásticas, sendo $2 / 3$ do comprimento das estacas imersos no substrato composto por areia lavada, previamente esterilizada por 60 minutos a $120^{\circ} \mathrm{C}$ em autoclave. As bandejas foram acondicionadas no viveiro $(70 \%$ de sombreamento) e a irrigação realizada diariamente de forma manual.

Aos 120 dias da instalação do experimento foram analisadas as seguintes características: percentual de estacas enraizadas e com brotações (\%); comprimento de raízes e de brotações, aferidos com régua graduada e expressos em milímetro (mm); número de raízes e de brotações, obtida por meio da contagem individual por estaca; massa fresca das raízes e das brotações, determinada com auxílio de balança analítica com precisão de $0,001 \mathrm{~g}$ e resultado em grama; e massa seca das raízes e das brotações, com auxílio de balança analítica com precisão de $0,001 \mathrm{~g}$, e resultado em gramas após secagem em estufa a $70^{\circ} \mathrm{C}$ por 72 horas.

Os dados obtidos foram então tabelados e calcularam-se as médias de cada grupo de estacas, ou seja, com e sem aplicação de AIB, as quais foram avaliadas 
por meio dos parâmetros estatísticos descritivos referente aos seus desvios-padrão e coeficientes de variação, utilizando-se o programa Microsoft Excel 2010.

\section{RESULTADOS E DISCUSSÃO}

Verificou-se que independente da aplicação de AIB a $9.000 \mathrm{mg} \mathrm{L}^{-1}$, a porcentagem de estacas enraizadas foi baixa, com média de 3,3 e 10,0\% para estacas sem tratamento e com tratamento, respectivamente (Tabela 1). Ainda que numericamente superior, quando considerados os desvios-padrão, observou-se que o uso de AIB não promoveu resultados mais eficientes do que aqueles obtidos na ausência de seu uso. Contudo, quando avaliada a porcentagem de brotação das estacas, o maior percentual de brotações foi obtido com estacas não tratadas, com média de $63,3 \pm 5,7 \%$ quando comparado com as estacas tratadas com AIB, com porcentagem média de $33,3 \pm 15,2 \%$ (Tabela 1 ).

TABELA 1. Médias, desvios-padrão e coeficientes de variação dos dados de desenvolvimento de estacas de umbuzeiro coletadas no período de repouso vegetativo. Serra Talhada-PE. 2020.

\begin{tabular}{ccccccc}
\hline Tratamento & $\begin{array}{c}\text { EE } \\
(\%)\end{array}$ & $\begin{array}{c}\text { EB } \\
(\%)\end{array}$ & $\begin{array}{c}\text { CR } \\
(\mathbf{c m})\end{array}$ & $\begin{array}{c}\text { CB } \\
(\mathbf{c m})\end{array}$ & NR & NB \\
\hline Sem AIB & $3,33 \pm 5,77$ & $63,33 \pm 5,77$ & $0,50 \pm 0,87$ & $3,86 \pm 3,34$ & $0,33 \pm 0,58$ & $1.44 \pm 0,36$ \\
Com AIB & $10,00 \pm 10,00$ & $33,33 \pm 15,28$ & $5,27 \pm 6,00$ & $7,34 \pm 2,46$ & $0,67 \pm 0,58$ & $1.11 \pm 0,19$ \\
\hline Média & 6,67 & 48,33 & 2,88 & 5,60 & 0,50 & 1,27 \\
CV (\%) & 70,71 & 43,89 & 116.90 & 43,91 & 47,14 & 18,06 \\
\hline
\end{tabular}

EE: porcentagem de estacas enraizadas. EB: porcentagem de estacas com brotações. CR: comprimento de raízes. CB: comprimento de brotações. NR: número de raízes. NB: número de brotações.

O baixo enraizamento de estacas de umbuzeiro já foi reportado na literatura por alguns autores. Rocha et al. (2019) obtiveram cerca de $11 \%$ de estacas enraizadas de umbuzeiro quando aplicadas $10 \mathrm{~g} \mathrm{~L}^{-1}$ de AIA durante 16 segundos de imersão. Estes mesmos autores verificaram médias inferiores quando utilizadas menores doses e tempo de imersão de 8 ou 24 segundos. Já Rios et al. (2012) obtiveram somente $30 \%$ de enraizamento de estacas de umbuzeiro com $20 \mathrm{~cm}$ de comprimento, com coleta realizada em março, quando submetidas ao tratamento com $6.000 \mathrm{mg} \mathrm{L}^{-1}$ de AIB. Por outro lado, Ataíde et al. (2017) não verificaram efeito significativo das doses de AIB sobre a porcentagem de estacas de umbuzeiro, enraizadas e com brotações, cultivadas em três substratos.

Os diferentes resultados observados podem ser devido ao fato que o efeito da aplicação exógena de auxinas sintéticas depende das concentrações endógenas do hormônio, bem como de outros compostos, como a concentração e disponibilização de carboidratos. No caso dos carboidratos, sabe-se que sua concentração em estacas é diretamente influenciada pelo período de coleta, de modo que em plantas caducifólias, antes da queda das folhas, a maior parte dos carboidratos é armazenada na forma de amido nas raízes (SOUZA et al., 2019). Portanto, isto pode estar relacionado aos baixos índices de enraizamento e brotação obtidos neste estudo, uma vez que as estacas foram coletadas durante o período de repouso vegetativo das plantas de umbuzeiro, quando as folhas já haviam caído.

Quando analisados os comprimentos de raízes e brotações, verificou-se que, numericamente, as médias obtidas a partir de estacas tratadas com AIB foram maiores. Porém, quando considerados os desvios-padrão, percebeu-se que o efeito 
deste regulador não foi significativamente efetivo sobre estas características (Tabela 1). O mesmo se aplica aos números de raízes e brotações emitidas, ainda que tenha havido maior número de raízes e menor número de brotações nas estacas tratadas com AIB (Tabela 1). Rios et al. (2012) reportam número de raízes $(0,24)$ inferior aos encontrados neste trabalho em estacas com $20 \mathrm{~cm}$ coletadas em setembro. De modo diferente, Rocha et al. (2019) obtiveram maior comprimento $(17 \mathrm{~cm})$ e número de raízes $(2,5)$ em estacas de umbuzeiro tratadas com $10 \mathrm{~g} \mathrm{~L}^{-1}$ de AIA.

Tendo em vista o baixo desempenho das estacas quanto aos números de raízes e brotos emitidos, verificaram-se poucas diferenças entre as estacas tratadas com e sem uso de AIB quanto à massa fresca e seca de raízes e brotações (Tabela 2). Além disso, os valores obtidos para ambos os grupos de estacas foram inferiores aos relatados por Rocha et al. (2019), Ataíde et al. (2017) e Rios et al. (2012). A massa fresca dos órgãos vegetais é composta, em sua maioria, por água, de modo que a massa seca é mais segura para efeitos de comparação, uma vez que é oriunda da soma de minerais e dos tecidos oriundos do crescimento. A produção de massa seca pela planta tem sido utilizada como fator relevante para avaliação da qualidade das mudas, no entanto, há o inconveniente da destruição total da planta para sua medição, inviabilizando-a em muitos viveiros (ARRIEL et al., 2006).

TABELA 2. Médias, desvios padrão e coeficientes de variação dos dados de massa fresca e seca de estacas de umbuzeiro coletadas no período de repouso vegetativo. Serra Talhada-PE. 2020.

\begin{tabular}{ccccc}
\hline Tratamento & MFR & MFB & MSR & MSB \\
\hline Sem AIB & $0,00 \pm 0,00$ & $2.34 \pm 3,31$ & $0,00 \pm 0,00$ & $0.150 \pm 0,086$ \\
Com AIB & $0.08 \pm 0,014$ & $0.80 \pm 0,75$ & $0.017 \pm 0,021$ & $0.074 \pm 0,065$ \\
\hline Média & 0,04 & 1,57 & 0,008 & 0,112 \\
CV (\%) & 141,42 & 69,10 & 141,42 & 47,88 \\
\hline
\end{tabular}

MFR: massa fresca de raízes. MFB: massa fresca de brotações. MSR: massa seca de raízes. MSB: massa seca de brotações.

\section{CONCLUSÕES}

O uso de AIB para a promoção do desenvolvimento de estacas de umbuzeiro coletadas no período de repouso vegetativo não foi eficiente na concentração de $9.000 \mathrm{mg} \mathrm{L}^{-1}$. Maior porcentagem de estacas brotadas é obtido na ausência do AIB, embora para os demais parâmetros não há diferenças significativas entre os dois grupos de estacas (com e sem AIB) quando se consideram os desvios das médias. Portanto, nestas condições, o uso de AIB não é recomendado.

\section{REFERÊNCIAS}

ANDRADE, M. W.; MENDONÇA, V.; HAFLE, O. M.; MEDEIROS, P. V. Q.; MENDONÇA, L. F. M. Adubos nitrogenados e potássicos na produção de portaenxertos de umbuzeiro (Spondias tuberosa Arr. Cam.). Revista Caatinga, Mossoró, v. 26, n. 4, p. 117-122, 2013. Disponível em: $<$ https://www.redalyc.org/articulo.oa?id=237129900014>.

ANTUNES, W. C.; MENDES, K.R.; CHAVES, A.R.M.; OMETTO, J.P.; JARMAOROZCO,.A.; Spondias tuberosa trees grown in tropical, wet environments are more susceptible to drought than those grown in arid environments. Revista Colombiana de Ciências Hortícolas, Boyacá, v. 10, n. 1, p. 9-27, 2016. Disponível em: 
ARAÚJO, J. L. P. Mercados. In: DRUMOND, M. A.; AIDAR, S. T. de; NASCIMENTO, C. E. SOUZA, de; OLIVEIRA, V. R. de. Umbuzeiro: avanços e perspectivas. Petrolina: Embrapa Semiárido, 2016, p. 243-266.

ARRIEL, E. F.; PAULA, R. C.; RODRIGUES, T. D. J. D.; BAKKE, O. A.; ARRIEL, N. $\mathrm{H}$. C. Divergência genética entre progênies de cnidoscolus phyllacanthus submetidas a três regimes hídricos. Científica, v. 34, n. 2, p. 229-237, 2006. Disponível em: <http://dx.doi.org/10.15361/1984-5529.2006v34n2p229++237>. doi: 10.15361/1984-5529.2006v34n2p229+-+237.

ATAÍDE, E. M.; SILVA, M.S.; SOUZA, J. M. A.; BASTOS, D. C. Ácido indolbutírico e substratos no desenvolvimento de estacas de umbuzeiro em três estádios fenológicos. Agrarian Academy, Centro Científico Conhece, Goiânia, v. 4, n. 8, p. 21-33, 2017.

Disponível em:

http://www.alice.cnptia.embrapa.br/alice/handle/doc/1087953>.

doi: 10.18677/Agrarian_Academy_2017b3.

COOPERCUC. Cooperativa Agropecuária Familiar de Canudos, Uauá e Curaçá. 2020. Disponível em: <www.coopercuc.com.br>. Acesso em: 01 Out. 2020.

DENAXA, N. K.; VEMMOS, S. N.; ROUSSOS, P. A. The role of endogenous carbohydrates and seasonal variation in rooting ability of cuttings of an easy and a hard to root olive cultivars (Olea europea L.). Scientia Horticulturae, v. 143, p. 1928, 2012. Disponível em: <https://doi.org/10.1016/j.scienta.2012.05.026>. doi: 10.1016/j.scienta.2012.05.026

LIMA, M. S. S.; DANTAS, A. C. V. L.; FONSECA, A. A. O.; BARROSO, J. P. Caracterização de frutos de genótipos selecionados de umbu-cajazeira (Spondias $s p$.$) . Interciencia, Caracas, v. 40, n. 5, p. 311-316, 2015. Disponível em:$ <https://www.redalyc.org/articulo.oa?id=33937066004>.

MENDES, N. V. B.; SOUZA, F. X. Rootstock species and scion types on Spondias mombin seedling formation porta-enxerto e tipo de enxerto na formação de mudas de cajazeira. Brazilian Journal of Development, v. 6, n. 10, p. 74550-74561, 2020. Disponível em: <https://doi.org/10.34117/bjdv6n10-035>. doi: 10.34117/bjdv6n10035.

MERTENS, J.; GERMER, J.; SIQUEIRA FILHO, J. A.; SAUERBORN, J. Spondias tuberosa Arruda (Anacardiaceae), a threatened tree of the Brazilian Caatinga. Brazilian Journal of Biology, v. 77, n. 3, p.1-11, 2016. Disponível em: <http://dx.doi.org/10.1590/1519-6984.18715>. doi: 10.1590/1519-6984.18715.

FONSECA, N.; CARDOSO, M. M.; RITZINGER, R.; LONDE, N. L. C.; GONÇALVES, N. P.; SATURNINO, H. M. Propagação do umbuzeiro. In: Umbuzeiro: a fruteira da Caatinga. Informe Agropecuário, Minas Gerais, v. 40, n. 307, p. 39-51, 2019. 
OINAM, G.; YEUNG, E.; KUREPIN, L.; HASLAM, T.; VILLALOBOS, A. L. Adventitious Root formation in ornamental plants: I. general overview and recent successes. Propagation of Ornamental Plants, v. 11, n. 2, p. 78-90, 2011. Disponível em: <http://www.journal-pop.org/2011_11_2_78-90.html>.

RIOS, E. S.; PEREIRA, M. C.; SANTOS, L. S.; SOUZA, T. C.; RIBEIRO, V. G. Concentrações de ácido indolbutírico, comprimento e época de coleta de estacas, na propagação de umbuzeiro. Revista Caatinga, v. 25, n. 1, p. 52-57, 2012. Disponível em: <https://periodicos.ufersa.edu.br/index.php/caatinga/article/view/2113>.

ROCHA, G. T.; SILVA, A. G.; MARTINS, J. B.; PEIXOTO, N; RODRIGUES, F. Vegetative propagation of Spondias tuberosa e Spondias dulcis with the use of immersion in indole acetic acid. Revista Caatinga, Mossoró, v. 32, n. 4, p. 858-866, 2019. Disponível em: <https://dx.doi.org//10.1590/1983-21252019v32n401rc >. doi:10.1590/1983-21252019v32n401.

SOUZA, F. X.; ARAÚJO, C. A. T. Avaliação dos métodos de propagação de algumas Spondias agroindustriais. EMBRAPA-CNPAT, Comunicado Técnico, 1999.

SOUZA, J. M. A.; LEONEL, S.; SOUZA, S. M.; JÚNIOR, M. D. A. O.; MARTINS, R. C.; BOLFARINI, A. C. B.; ATAÍDE, E. M. Carbohydrate content and season collection of cuttings from 'Roxo de Valinhos' fig tree. Comunicata Scientiae, v. 10, n.1, p. 25131, 2019. Disponível em: <https://doi.org/10.14295/cs.v10i1.2902>. doi: 10.14295/cs.v10i1.2902.

TECCHIO, M. A.; LEONEL, S.; REIS, L. L.; SIMONETTI, L. M.; SILVA, M. J. R. Stimulate no desenvolvimento de mudas de Kunquat 'Nagami'. Irriga, edição especial p.97-106, 2015.2 Disponível em: <http://dx.doi.org/10.15809/irriga.2015v1n1p97>. doi: 10.15809/irriga.2015v1n1p97.

VÉRAS, M. L. M.; MENDONÇA, R. M. N.; SILVA, S. M.; FIGUERED0, L. F.; ARAUJO, V. L.; PEREIRA, W. E.; MELO FILHO, J. S.; ANDRADE, R. Propagation of Umbuzeiro (Spondias tuberosa Arr. Cam.), a native plant to Brazilian semi-arid regions, using ethephon and indolebutyric acid (IBA). Australian Journal of Crop Science, v.12, n.04, p.602-609, 2018. Disponível em: <https://www.cropj.com/veras_12_4_2018_602_609>. doi: 10.21475/ajcs.18.12.04.pne888. 